Mini-Review or Systematic Review

\title{
Physical, psychological and demographic factors associated with military discharge: a systematic review
}

\author{
Gabriel Luis Moreira Fidelis $^{1,2,3}$ (D), Maria Elisa Koppke Miranda ${ }^{1,2,3}$ (D), \\ Priscila dos Santos Bunn ${ }^{1,2,3}$ \\ ${ }^{1}$ Marinha do Brasil, Centro de Educação Física Almirante Adalberto Nunes, Laboratório de \\ Pesquisa de Ciências do Exercício, Rio de Janeiro, RJ, Brasil; ${ }^{2}$ Universidade da Força Aérea, \\ Programa de Pós-Graduação em Desempenho Humano Operacional, Rio de Janeiro, RJ, Brasil; \\ ${ }^{3}$ Universidade do Estado do Rio de Janeiro, Instituto de Educação Física e Desportos, Programa \\ de Pós-Graduação em Ciências do Exercício e do Esporte, Rio de Janeiro, RJ, Brasil.
}

Associate Editor: Romulo A Fernandes, Universidade Estadual Paulista "Júlio de Mesquita Filho", Presidente Prudente, SP, Brazil.

\begin{abstract}
Aims: The present study is a review focused on analyzing the physical, psychological, and demographic factors that lead recruits to be dismissed or to request their dismissal during basic military training periods. Methods: This study is a systematic review of cohort studies. The following databases were searched in June 2019 and updated in July 2020: Embase, LILACS, CINAHL, Cochrane, MEDLINE, SCOPUS, SPORTDiscus, Web of Science, and Science Direct databases. The MeSH descriptors military personnel, risk factors, and discharge were used to elaborate the search equations. Reference lists were explored to find studies that examined the association between physical, psychological, and demographic factors that lead recruits to be discharged. The following data were extracted from the studies: profile of the participants, sample size, type of risk factors, the duration of follow-up, and the results of the statistical analysis carried out in the studies included. The risk of bias was analyzed with the Newcastle-Ottawa Scale for cohort studies. Results: A total of 531 titles were retrieved from the databases, and eight articles met the eligibility criteria. The results showed the factors associated with discharge, in descending order: musculoskeletal injuries and other medical questions, depressive and behavioural disorders, performance in physical fitness tests, and others. Factors such as educational level, alcohol use, history of suicide attempt, and imprisonments were not associated with an increased risk of being discharged. Conclusion: Musculoskeletal injuries, depression, running performance, previous physical exercise practice, and demographic factors were associated with an increased risk of being discharged.
\end{abstract}

Keywords military personnel, risk factors, discharge.

\section{Introduction}

Discharge is the term used when referring to training military when a withdrawal is requested by recruits for various reasons, resulting in the military personnel being disconnected from the basic training period before it is completed $^{1}$.

Being prematurely discharged from the Army Basic Training of the United States of America (ABT) is a concern, as it generates a loss of resources for the recruits and their training, as well as the reduction of readiness and institutional workforce. Fort Jackson, North Carolina - the US - has the largest number of soldiers in ABT. Statistics of this recruitment center indicate that during the fiscal year of $1998,15 \%$ of recruits were discharged before the basic period was complete, $18 \%$ of trained soldiers left the army before completing six months on active duty, and $36 \%$ did not see through the service period in the contracts signed with the Army ${ }^{2}$.
The basic training of the United States Marine Corps (USMC) involves physical and varied demanding challenges created to train the recruits to successfully develop activities useful for military service. Due to the high degree of physical overload and the low level of fitness of the recruits, there is a high incidence of injuries in the initial training, that are associated with an elevated number of recruits who are discharged from military service ${ }^{3}$.

To illustrate in numerical terms, the US Army's Department has found that musculoskeletal injuries are the biggest obstacle faced while maintaining military readiness, and approximately $25 \%$ of the men and $50 \%$ of female recruits suffer one or more injuries during the initial training period, and these injuries account for over $80 \%$ of personnel being disconnected for failing during the first year of recruitment. Thus, the relevance of these facts must be taken into account as the cost associated with a recruit was estimated at $\$ 57,500^{4}$. 
At the same time, it points out is that there are also social factors linked to the risk of being discharged from military organizations. Level of education, marital status, age, and the number of children can be taken into account when deciding to withdraw from a military career ${ }^{5}$. In this list of factors that affect the performance of military personnel and may lead them to quit, are also behavioral factors, such as smoking and prior lifestyle ${ }^{6}$.

In Taiwan, conscription has been practiced for many years, and the majority of Taiwanese citizens are listed for recruitment in the armed forces, and their training focuses on the security of the country and its people, which require superior psychological and physical abilities. Within the major categories of disease, studies show mental problems have the greatest impact on the performance and readiness of soldiers, as well as play a considerable role in the discharge from military service ${ }^{7}$.

The literature points to factors such as musculoskeletal injuries ${ }^{8}$, age $^{9}$, gender ${ }^{10}$, psychological factors ${ }^{7}$, etc. as being associated with a higher risk of retirement. However, there is a contradiction between the results of some studies $^{9-11}$. In addition, the studies compiled address different risk factors, making it difficult to predict success rates during training. However, until the completion of the present review, no other reviews have been found that consolidate the results of different studies and that could guide strategies. Given the high cost of each military personnel, the diversity of factors associated with loss of mental and physical performance have a direct relationship between the occurrence of these factors and military discharges. The purpose of this study was to investigate which factors are related to being discharged from military service and which, if any, factors were predominant. Thus, it is expected that in the future preventative measures can be developed preventive measures to reduce attrition in training courses in military units. It is assumed that recruits with poor or no history of physical exercise, those with injuries, and those who have psychological or sociodemographic characteristics that prioritize their stay in the course present lower attrition.

\section{Methods}

\section{Study design and sample}

The present systematic review was based on the Preferred Reporting Items for Systematic Reviews and MetaAnalysis recommendation (PRISMA) ${ }^{12}$ and registered at the Open Science Framework (https://osf.io/xv3wy/).

\section{Eligibility criteria}

The inclusion criteria in the present systematic review were prospective cohort studies that investigated the risk factors that led military personnel to give up a career in the armed forces of different countries, being in training courses, or training in military units.

\section{Search strategy}

We searched without taking into consideration time and language filters in June of 2019 and updated in July of 2020, using the databases EMBASE, Web of Science, SPORTDiscus, Cumulative Index to Nursing and Allied Health Literature (CINAHL), US National Library of Medicine (MEDLINE), Science Direct, Cochrane, Latin American \& Caribbean Health Sciences Literature (LILACS), and SCOPUS. Search descriptors used were military personnel, risk factors, discharge. Search phrases were obtained using the Boolean operators "AND" (between descriptors) and "OR" (between synonyms). In those cases, date limits or language filters were applied.

\section{Data collection process}

Data extracted from the studies were: the profile of the participants, the sample size, the various risk factors for military discharge, the follow-up, and the results of statistical analysis.

\section{Selection of the studies}

Two authors selected the titles and abstracts independently. After, full texts that met the inclusion criteria were analyzed. Disagreements were solved by consensus.

\section{Risk of bias of the studies}

For the analysis of the risk of bias, the NewcastleOttawa Scale (NOS) for cohort studies ${ }^{9,10}$ was used, as all studies included in this review were prospective. NOS consists of three domains with their scoring criteria: 1) selection (representative of the exposed cohort, selection of non-exposed cohort, exposure assessment, absence of cases in the baseline); 2) comparison (paired main variables and others); and 3) results (evaluation of the results, sufficient follow-up time, and adequacy of follow-up of cohorts). A star was attributed for each topic of studies evaluated with a low risk of bias. Studies with a total of fewer than five stars were classified as "high risk" of bias. Studies were considered "uncertain" risks when they didn't score any points in the "comparison" domain. The remaining studies were classified as "low risk of bias".

\section{Results}

\section{Overview}

The flow diagram of the included studies is shown in Figure 1. The search phrases used in the databases are shown in Table 1. A total of 534 articles were identified after an extensive search using the database of electronic research and 99 duplicate titles were removed. 411 studies did not meet the inclusion criteria and were excluded. 


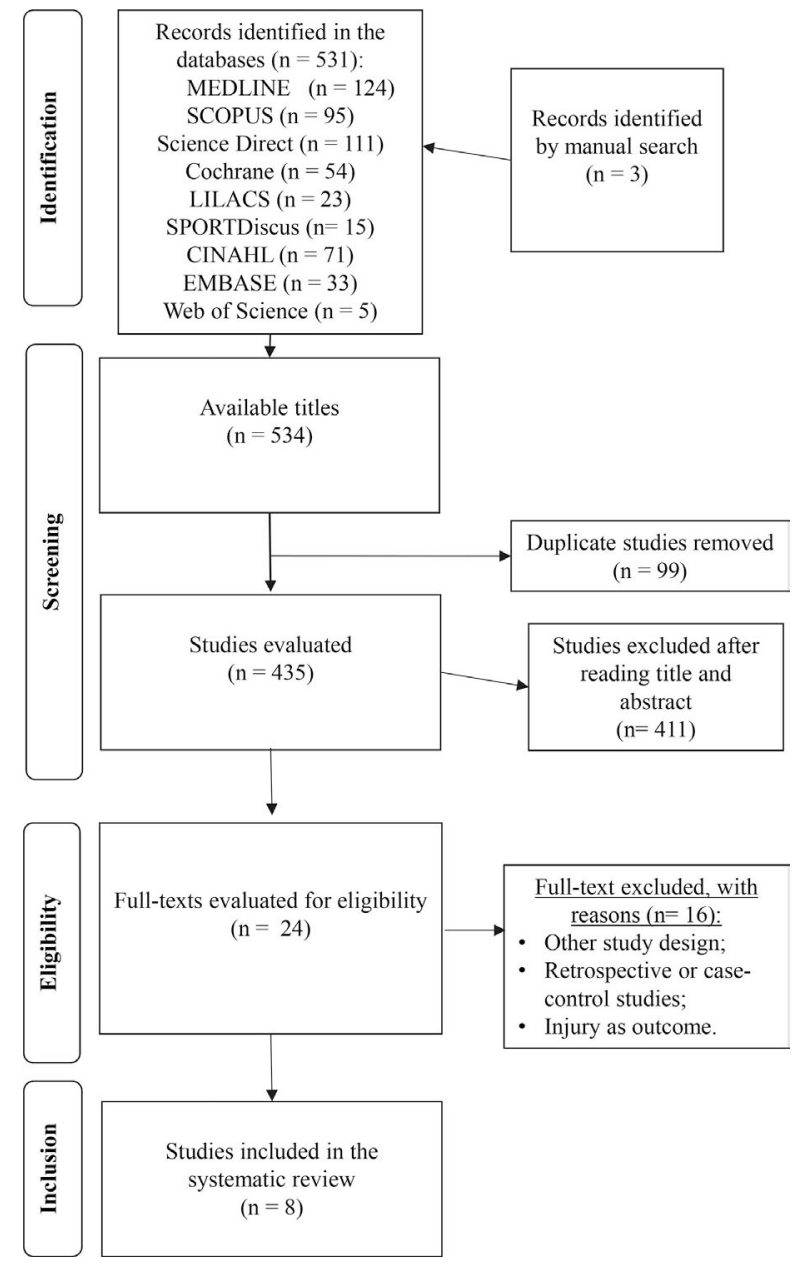

Figure 1 - Flow diagram of the included studies.
Eight studies involving a total of 43.386 participants met the inclusion criteria for the review. All the studies were published in scientific peer-reviewed journals. The characteristics of the study are included in Table 2, and evaluation of the risk of bias, in Table 3.

\section{Discussion}

The results of this systematic review showed that several risk factors are related to attrition in military training courses. Attrition factors observed were musculoskeletal injuries (stress fractures and other injuries in the lower limbs and trunk), age, non-Hispanic race, poor physical fitness, lack of previous sports practice, and psychological problems (major depression, mental impairment, depression, bipolar II, and personality disorders). However, it is noteworthy that physical factors were predominant (injury or performance in physical tests) (Table 2). Although the samples were composed of recruits, participants were included from different forces in different studies (marines, Army, and Air Force). The studies included participants from different countries such as Taiwan, Australia, the USA, and Sweden. At the same time, the duration of the courses varied from two to 12 months.

In the next paragraphs, the main factors associated with a premature discharged from the military basic training courses were discussed, with possible preventive or corrective measures in order to avoid the numerous occurrences of attrition during adaptation periods to military routine.

Table 1 - Search phrases utilized in the databases

\begin{tabular}{|c|c|}
\hline Database & Search phrase \\
\hline MEDLINE & $\begin{array}{l}(((((()(((((\text { risk factor)[Title/Abstract] OR risk factors)[Title/Abstract] OR population at risk)[Title/Abstract] OR risk, population at) } \\
\text { [Title/Abstract] OR populations at risk)[Title/Abstract] OR risk, populations at)[Title/Abstract] OR factors, risk)[Title/Abstract] OR } \\
\text { factors risk))[Title/Abstract] OR factor)[Title/Abstract] OR factors[Title/Abstract])) AND ((((marines)[Title/Abstract] OR soldier) } \\
\text { [Title/Abstract] OR soldiers)[Title/Abstract] OR marine[Title/Abstract])) AND ((attrition)[Title/Abstract] OR discharge[Title/Abstract]) }\end{array}$ \\
\hline LILACS & marine or marines or soldier or soldiers [Palavras] and attrition or discharge [Palavras] \\
\hline Science Direct & (marine or soldier) AND (Attrition or discharge) AND factor \\
\hline SCOPUS & $\begin{array}{l}\text { (TITLE-ABS-KEY ("Risk factor" OR “Factor, Risk" OR “Factors, Risk” OR "Population at Risk")) AND (TITLE-ABS-KEY (“attri- } \\
\text { tion" OR “discharge")) AND (TITLE-ABS-KEY (“Marines" OR "Soldier" OR “Soldiers")) }\end{array}$ \\
\hline Cochrane & $\begin{array}{l}\text { marine or marines or soldier or soldiers in Title Abstract Keyword AND attrition or discharge in Title Abstract Keyword - (Word varia- } \\
\text { tions have been searched) }\end{array}$ \\
\hline SPORTDiscus & $\begin{array}{l}\text { AB ("risk factor" OR "risk factors" OR "population at risk" OR "populations at risk" OR "factors risk" OR factor OR factors") AND } \\
\text { AB (marines OR soldier OR soldiers OR marine) AND AB (attrition OR discharge) }\end{array}$ \\
\hline CINAHL & $\begin{array}{l}\text { AB ("risk factor" OR "risk factors" OR "population at risk" OR "populations at risk" OR "factors risk" OR factor OR factors") AND } \\
\text { AB (marines OR soldier OR soldiers OR marine OR military) AND AB (attrition OR discharge) }\end{array}$ \\
\hline $\begin{array}{l}\text { Web of Sci- } \\
\text { ence }\end{array}$ & $\begin{array}{l}\text { TÍTULO: (“risk factor” OR “risk factors” OR "population at risk" OR “populations at risk” OR "factors risk” OR factor OR factors) } \\
\text { AND TÍTULO: (marines OR soldier OR soldiers OR marine OR military OR “military personnel”) AND TÍTULO: (attrition OR dis- } \\
\text { charge) } \\
\text { Tempo estipulado: Todos os anos. Índices: SCI-EXPANDED, SSCI, A\&HCI, CPCI-S, CPCI-SSH, ESCI. }\end{array}$ \\
\hline Embase & $\begin{array}{l}\text { ('risk factor':ab,ti OR 'risk factors':ab,ti OR 'population at risk':ab,ti OR 'populations at risk':ab,ti OR 'factors risk':ab,ti) AND (mar- } \\
\text { ines:ab,ti OR soldier:ab,ti OR soldiers:ab,ti OR marine:ab,ti) AND (attrition:ab,ti OR discharge:ab,ti) }\end{array}$ \\
\hline
\end{tabular}


Table 2 - Characteristics of studies included in the systematic review.

\begin{tabular}{|c|c|c|c|c|}
\hline Author & Sample & Risk factor & Results & $\begin{array}{c}\text { Follow- } \\
\text { up }\end{array}$ \\
\hline $\begin{array}{l}\text { Reis et al. } \\
(2007)\end{array}$ & $\begin{array}{l}\mathrm{n}=2,137 \text { recruits the body of } \\
\text { US Marines }\end{array}$ & $\begin{array}{l}\text { Physical characteristics, socio data - } \\
\text { demographic, history of physical exercise } \\
\text { and injuries }\end{array}$ & $\begin{array}{l}\text { Stress fracture during training, age }>23 \text { years, not } \\
\text { a Hispanic race, poor self-reported physical fitness } \\
\text { without competitive exercise history, and previous } \\
\text { injury in the lower limbs were associated with a } \\
\text { higher risk of discharge }(\mathrm{P}<0.05) \text {. }\end{array}$ & $\begin{array}{c}12 \\
\text { weeks }\end{array}$ \\
\hline $\begin{array}{l}\text { Chang et al. } \\
(2008)\end{array}$ & $\mathrm{n}=1,912$ recruits Taiwanese & Mental disorders & $\begin{array}{l}\text { Depressive disorders such as major depression, } \\
\text { mental failure, type II bipolar depression, and per- } \\
\text { sonality disorders were associated with a greater } \\
\text { number of lower }(\mathrm{P}<0.05) \text {. }\end{array}$ & $\begin{array}{c}12 \\
\text { months }\end{array}$ \\
\hline $\begin{array}{l}\text { Pope et al. } \\
\text { (1999) }\end{array}$ & $\mathrm{n}=1,317$ Australian recruits & 2 miles run performance or injury. & $\begin{array}{l}\text { A multivariate analysis was performed. Age was } \\
\text { not associated with a greater number of casualties. } \\
\text { Recruits who have suffered an injury and the } \\
\text { worst-performing Yo-Yo test were considered at } \\
\text { high risk of attrition. }\end{array}$ & $\begin{array}{c}12 \\
\text { weeks }\end{array}$ \\
\hline $\begin{array}{l}\text { Swedler et al. } \\
\text { (2011) }\end{array}$ & $\mathrm{n}=4,005$ Recruits US Army & $\begin{array}{l}\text { Psychosocial and historical factors of } \\
\text { physical activity. }\end{array}$ & $\begin{array}{l}\text { Women had a higher risk than men with } \mathrm{HR}=2.76 \\
(95 \% \mathrm{CI}=2.04-3.74) \text { of attrition. There were fac- } \\
\text { tors associated with both sexes (divorced marital } \\
\text { status or separated, and failure on bar fitness test), } \\
\text { for females (age, Caucasian ethnicity, and BMI } \\
\text { between } 25 \text { and } 29 \mathrm{~kg} / \mathrm{m}^{2} \text { ) and males (lower inju- } \\
\text { ries and poor historical of exercise). }\end{array}$ & $\begin{array}{c}2 \\
\text { months }\end{array}$ \\
\hline $\begin{array}{l}\text { Larsson et al. } \\
\text { (2009) }\end{array}$ & $\begin{array}{l}\mathrm{n}=469 \text { Army military } \\
\text { Swedish }\end{array}$ & Injuries and psychosocial factors & $\begin{array}{l}\text { Recruits who reported injuries early in the course } \\
\text { were more associated with discharge. } 56 \% \text { of } \\
\text { which were lower were considered physically } \\
\text { inactive in the period prior to enrollment. The habit } \\
\text { of smoking significantly was more present in the } \\
\text { case of discharge. }\end{array}$ & $\begin{array}{c}12 \\
\text { months }\end{array}$ \\
\hline $\begin{array}{l}\text { Talcott et al. } \\
\text { (1999) }\end{array}$ & $\begin{array}{l}\mathrm{n}=32,144 \text { recruits of the US } \\
\text { Air Force. }\end{array}$ & Medical and psychological reasons & $\begin{array}{l}\text { The most associated with discharge factors were, } \\
\text { in descending order: medical reasons, followed by } \\
\text { psychological or behavioral, administrative or } \\
\text { legal reasons, and last underperforming. }\end{array}$ & $\begin{array}{c}12 \\
\text { months }\end{array}$ \\
\hline $\begin{array}{l}\text { Elbogen et al. } \\
(2018)\end{array}$ & $\begin{array}{l}\mathrm{n}=1,172 \text { Iraq/Afghanistan- } \\
\text { era veterans were evaluated } \\
\text { between } 2005 \text { and } 2016\end{array}$ & $\begin{array}{l}\text { Demographic, military, historic, clinical, } \\
\text { and situational characteristics from veter- } \\
\text { ans discharged under honorable condi- } \\
\text { tions }\end{array}$ & $\begin{array}{l}\text { Factors associated with discharge: } \\
\text { Older age - reduced odds of discharge }(0.95 ; \\
\mathrm{P}=0,046) ; \text { Higher level of education - reduced odds } \\
\text { of discharge }(\mathrm{OR}=0.95 ; \mathrm{P}=0,053) \text {; Family history } \\
\text { of depression }(\mathrm{OR}=2.18 ; \mathrm{P}=0,03) \text { or drug abuse } \\
(\mathrm{OR}=2.16 ; \mathrm{P}=0,034), \text { living status and community } \\
\text { function }(\mathrm{OR}=0.99, \mathrm{P}=0,042) \text {, unmarried status } \\
(0.43 ; \mathrm{P}=0,032) \text { and report of past incarceration } \\
(\mathrm{OR}=4.25 \text { e } \mathrm{P}=0,0001) . \text { Sleep problems ( } \mathrm{OR}=0.46 \text {; } \\
\mathrm{P}=0,019) \text {. } \\
\text { Factors without association with discharge: factors } \\
\text { in the domains of trauma and military history, gen- } \\
\text { der, race, education, alcohol, attempt of suicide, } \\
\text { prison, and other health/psychiatric problems. }\end{array}$ & - \\
\hline $\begin{array}{l}\text { Wunderlin } \\
\text { et al. (2015) }\end{array}$ & $\begin{array}{l}\mathrm{n}=230 \text { male recruits in a } \\
\text { Swiss Anny fusilier company }\end{array}$ & $\begin{array}{l}\text { Global trunk muscle strength (TMS) and } \\
\text { sit-up tests }\end{array}$ & $\begin{array}{l}\mathrm{AUC}=0.60 \text { and } \mathrm{P}=0.11 \text { (TMS) and } \mathrm{AUC}=0.50 \\
\text { and } \mathrm{P}=1.00 \text { (sit-up) }\end{array}$ & $\begin{array}{c}13 \\
\text { weeks }\end{array}$ \\
\hline
\end{tabular}

$\mathrm{OR}=$ odds ratios; $\mathrm{AUC}=$ area under the Receiver Operating Characteristic Curve; $\mathrm{HR}=$ hazard ratios.

\section{Musculoskeletal injuries}

Musculoskeletal injuries during military training were the main cause of discharge reported by the stu$\operatorname{dies}^{16}$. A possible explanation is that individuals who are less conditioned and go through the courses have a higher risk of injury, making them more likely to be discharged ${ }^{8}$, as well as developing a new injury during training ${ }^{16}$. Therefore, this can result in a considerable financial impact on the armed forces since the demand spent on medical consultations, examinations, and rehabilitation treatments is high. After an injury, some recruits may not return to their original training groups, which make up their social ties and that affects the morale, as well as creates uncertainty, fear, and frustration ${ }^{3}$. The injuries are defined as any damage to the musculoskeletal system, which has required medical attention, associated with 
Table 3 - Risk of bias of the studies with the Newcastle-Ottawa Scale for cohort studies.

\begin{tabular}{|c|c|c|c|c|c|c|c|c|c|c|c|}
\hline Author & 1 & 2 & 3 & 4 & 5 & 6 & 7 & 8 & 9 & Score & Risk \\
\hline Reis et al. (30) & $*$ & * & * & $*$ & $*$ & $*$ & & $*$ & $*$ & 8 & Low \\
\hline Chang et al. (7) & $*$ & & * & $*$ & $*$ & $*$ & & $*$ & $*$ & 7 & Low \\
\hline Pope et al. (11) & $*$ & $*$ & $*$ & $*$ & $*$ & & & $*$ & $*$ & 7 & Low \\
\hline Swedler et al. (34) & $*$ & * & * & * & $*$ & $*$ & & & $*$ & 7 & Low \\
\hline Larsson et al. (21) & $*$ & $*$ & $*$ & $*$ & $*$ & $*$ & & $*$ & $*$ & 8 & Low \\
\hline Talcott et al. (8) & $*$ & $*$ & & * & $*$ & $*$ & & $*$ & $*$ & 7 & Low \\
\hline Elbogen et al. (10) & * & * & $*$ & * & * & $*$ & $*$ & & $*$ & 8 & Low \\
\hline Wunderlin et al. (27) & & $*$ & & $*$ & & & $*$ & $*$ & $*$ & 5 & Uncertain \\
\hline
\end{tabular}

Domains of the Newcastle-Ottawa Scale (NOS): Selection (1 - representativeness of the exposed cohort; 2- selection of the non-exposed cohort; 3 ascertainment of exposure; 4 - demonstration that the outcome of interest was not present at the start of the study); Comparability (5- principal factor and 6- any additional factor); and Outcome (7 - assessment of outcome; 8 - if the follow-up was long enough for outcomes to occur; and 9-adequacy of follow-up cohorts).

sport or operational practice, and that have promoted removal or forced adaptation to functions previously executed for more than 24 hours $^{17}$. In order to improve the rehabilitation of military personnel, the USMC has the Military Platoon Recovery (MRP), where the military with severe injuries are removed from their platoons of origin to be accompanied by doctors, physiotherapists, and physical trainers to assist recovery. The military personnel that enter this squad is very likely to be discharged from military service since they are removed from their usual routine and lose the social bond with their other partners. This causes severe damage to the morale of these soldiers. In addition to this, these military face the uncertainty of returning to normal routine activities, which also greatly contributes to the psychological stress and a possible request to be voluntarily discharged ${ }^{3}$. At the same time, readiness is reduced as some military are discharged and others are unable to fulfill their calling due to temporary injuries. Implementing preventative strategies and actions, such as carrying out early diagnosis, results in a quicker return to activities ${ }^{18}$.

Some studies show that 6-8 percent of recruits are injured per month during basic periods of recruitment, which brings the need to prevent most of this situation in order to increase productivity and combat readiness in barracks. As the running activity was observed to be a high-risk activity of musculoskeletal injuries in the North American army, some measures taken by the Army Public Health Center (APHC) in order to prevent such injuries, increase in the exercise involving multivariate joints, exercises on the grass, progression drills, and precision movements ${ }^{19}$.

\section{Psychological factors}

One of the risk factors found in this review was the mental health. It is a very difficult factor to prevent, as there is some inevitable subjectivity in the screening process to identifying pre-and post-entry conscripts at risk into the military careers. With the growing need for reductions in military spending, it has become increasingly important to effectively maintain the quality of human resources in the military environment. This emphasis has led to concerns in recent years regarding the effectiveness of current procedures for screening military recruits. Screening procedures, however, can prevent some healthy recruits from developing symptoms that may affect individuals as well as the performance of the unit as a whole.

One factor that may undermine military adaptability is psychopathology as a result of stressors in basic training recruits. Anxiety and depressive symptoms can manifest themselves in vulnerable individuals in stressful situations such as the ones recruits witness every day during training orders, the physical requirements, and individual and collective challenges faced. Several theories put specific risk factors as vulnerability factors ${ }^{20}$. Some disorders can decrease motivation ${ }^{21}$. Intrinsic motivation is associated with physical performance, including tolerance to increased training loads and physical fitness ${ }^{22}$. As the number of complaints increases, recruits become more worried about the situation. This fact is especially common in the injured recruits ${ }^{21}$. Moreover, recruits with better aerobic conditioning show less psychosocial stress respons $^{22}$. Other authors have shown that psychological stress seems to be a precursor to being discharged ${ }^{21}$.

Given the considerable possibility of a recruit having some psychopathology after analysis procedures during entry screening, it was found that false answers were given by candidates in questionnaires and interviews, as well as memorized ones. Questions such as a history of depression or suicidal thoughts do not reflect the truth in many cases, which impairs the admission process and lets candidates with serious problems go through recruitment. To prevent this type of occurrence, some measures can be taken by the recruiter's team, such as a briefing with all candidates emphasizing the importance of being true and faithful in their answers in the questionnaires ${ }^{23}$. 


\section{History of pre-recruitment physical exercises}

At least three articles of this review listed as a risk factor for attrition, the history of physical exercises, so it is an important factor to be analyzed and exploited in order to prevent discharges. It is common for individuals with different levels of conditioning to join military service ${ }^{22}$. When the recruits are subjected to intense training loads, the risk of injury increased, especially in the lower limbs ${ }^{23-25}$. However, performance in the global trunk muscle strength and sit-up tests were not associated with the attrition ${ }^{27}$.

Gradual increases in training load and the load control may be a strategy to prevent injuries ${ }^{25}$. A progressive increase in the training load must be carefully planned during the initial training period. Progression can only be achieved through some level of individualized training. An option to adapt recruits with low physical fitness to the stress of military training is a previous training phase that takes place before the basic military training. Some individualization can be achieved by dividing the recruits into groups according to their initial fitness level at the start of the basic training period. Subsequently, adjustments can be made in full training load by varying the volume and intensity of exercise between the groups. This method can result in improvements in the fitness of recruits ${ }^{26}$.

As an alternative to mitigate discharge because of this is a type of program that has been used in four companies of the Pori Brigade - Finland, where conscripts performed 8 weeks of activities such as running, speed (long walks), swimming, fights, and others. In the first month, every week had 17 hours of training gradually increasing the level of physical demand. In parallel, the recruits had 7 hours per week of some fun activities as individual and team sports and during most of the period, the level of intensity was low and could be increased to moderate. In the second month, the military training period started merging different types of physical activity depending on the company that they belonged ${ }^{27}$.

\section{Socio-demographic factors}

Some social and demographic factors stood out in our studies. The authors analyzed a possible reason as to why recruits from the European American Ethnicity were more associated with discharges than those of minority ethnic origin such as Afro-Americans. This may be associated with the motivation of each ethnic group to enter the armed forces: probably, the European ethnicity faces the military service as something temporary, that serves as a ladder to other professions, while ethnic minorities consider the possibility of serving the military as a career opportunity and as a chance to escape the hard life of the cities $^{21}$. Another interesting fact is the influence of age on the risk of attrition, where a contradiction in two of the listed studies can be noticed, one of which shows age as a low factor and the other which does not highlight such an association. This contradiction is clear, however, associations both negative and positive are numerically very small, and apparently not significant to the risk of being discharged ${ }^{11,12}$. In general, some minorities might see that the military career is an opportunity because of fewer options outside of the military ${ }^{8,10}$.

\section{Limitations and Strong points of the study}

This review is not without limitations. First, the articles maintain the same line of thought, and that their results don't differ much in general. The studies generally conclude by presenting factors more closely associated with attrition. However, the studies did present possible solutions to prevent these attritions, providing examples of preventive measures for each case that resulted in discharge.

This review presented high heterogeneity among the studies. The samples were composed by participants of different countries and troops with different characteristics. It increases the risk of bias since different troops from different countries carry different genes, thoughts, and behavior (due to their cultures).

Although nine different research bases were used and more than 500 titles came up during search results, the present study found only eight titles that met the inclusion criteria. However, the synonyms available in DeCS and $\mathrm{MeSH}$ were used, as well as the keywords of articles published on the subject.

Due to the diversity of factors found and the lack of standardization of the results presented, it was not possible to extract data that allowed the conduction of a meta-analysis and, therefore, an analysis of the size of the effect of each risk factor, the risk of publication bias, as well as their level of evidence ${ }^{28-30}$.

However, the present review has as strengths the extensive search in various databases on the subject, selection of titles independently, as well as a careful and methodological assessment. In this regard, most studies had a low risk of bias, which increases confidence in the results obtained.

\section{Conclusions}

Several risk factors were associated with premature military discharge in different countries. The main reasons were musculoskeletal injuries, physical and psychological factors. We suggest conducting evaluations of recruits, including an investigation of the factors most associated with casualties, such as honesty when filling out psychometric questionnaires and admission interviews, physical training programs directed and controlled, with a gradual increase of load and volume as an effective strategy to reduce the risk of discharge from the courses, especially in cases of recruits that don't have a history of practicing 
exercises, rehabilitation programs for military injuries and the existence of an initial physical training period before the Basic Military Training.

Finally, considering the demographic impact on the risk of being discharged, and the lack of studies in developing countries, there seems to be a possible space to investigate the peculiarities and results related to this subject in such locations. Therefore, new studies should investigate the predictive factors for discharge. As a result, specific preventative strategies can be planned for each location.

\section{References}

1. Larsson H. Premature discharge from military service: Risk factors and preventive interventions. Institutionen för neurobiologi, vårdvetenskap och samhälle/Department of Neurobiology, Care Sciences and Society, 2009.

2. Knapik JJ, Canham-Chervak M, Hauret K, Hoedebecke E, Laurin MJ, Cuthie J. Discharges during U.S. Army basic training: Injury rates and risk factors. Mil Med [Internet]. 2001;166(7):641-7.

3. Booth-Kewley S, GE L, RM H-M, Booth-Kewley S, Larson GE, Highfill-McRoy RM. Psychosocial predictors of return to duty among marine recruits with musculoskeletal injuries. Mil Med [Internet]. 2009;174(2):139-52.

4. Molloy JM, Feltwell DN, Scott SJ, Niebuhr DW. Physical training injuries and interventions for military recruits. Mil Med. 2012;177(5):553-8.

5. Piccirillo AL, Packnett ER, Cowan DN, Boivin MR. Risk factors for disability discharge in enlisted active-duty Army soldiers. Disabil Health J. 2016;9(2):324-31.

6. Larsson H, Broman L, Harms-Ringdahl K. Individual Risk Factors Associated with Premature Discharge from Military Service. Mil Med. 2013;174(1):9-20.

7. Chang H-A, Shiah I-S, Chang C-C, Chen C-L, Huang S-Y. A study of prematurely discharged from service and related factors in Taiwanese conscript soldiers with mental illness. $\mathrm{J}$ Med Sci [Internet]. 2008;28(1):15-25.

8. Talcott GW, Haddock CK, Klesges RC, Lando H, Fiedler E. Prevalence and predictors of discharge in the United States Air Force Basic Military Training. Mil Med. 1999;164 (4):269-74.

9. Orr RM, Cohen BS, Allison SC, Bulathsinhala L, Zambraski EJ, Jaffrey M. Models to predict injury, physical fitness failure and attrition in recruit training: A retrospective cohort study. Mil Med Res [Internet]. 2020;7(1).

10. Elbogen EB, Wagner HR, Brancu M, Kimbrel NA, Naylor JC, Swinkels CM, et al. Psychosocial Risk Factors and Other Than Honorable Military Discharge: Providing Healthcare to Previously Ineligible Veterans. Mil Med. 2018;183(9-10):E532-8.

11. Pope RP, Herbert R, Kirwan JD, Graham BJ. Predicting attrition in basic military training. Mil Med. 1999;164 (10):710-4.

12. Moher D, Liberati A, Tetzlaff J, Altman DG, Grp P. Preferred Reporting Items for Systematic Reviews and MetaAnalyses: The PRISMA Statement. Phys Ther. 2009;89 (9):873-80.
13. Wells GA, Shea B, Connell DO, Peterson J, Welch V, Losos M, et al. The Newcastle-Ottawa Scale ( NOS ) for assessing the quality of nonrandomised studies in meta-analyses [Internet]. 2000. p. 1-3.

14. Margulis A, Pladevall M, Riera-Guardia N, Varas-Lorenzo C, Hazell L, Berkman N, et al. Quality assessment of observational studies in a drug-safety systematic review, Comparison of two tools: The Newcastle-Ottawa scale and the RTI item bank. Clin Epidemiol. 2014;6:981-93.

15. Wardle SL, Greeves JP. Mitigating the risk of musculoskeletal injury: A systematic review of the most effective injury prevention strategies for military personnel. J Sci Med Sport [Internet]. 2017;20:S3-10.

16. Teyhen DS, Rhon DI, Butler RJ, Shaffer SW, Goffar SL, McMillian DJ, et al. Association of Physical Inactivity, Weight, Smoking, and Prior Injury on Physical Performance in a Military Setting. J Athl Train (Allen Press [Internet]. 2016;51(11):866-75.

17. Hägglund M, Waldén M, Bahr R, Ekstrand J. Methods for epidemiological study of injuries to professional football players: developing the UEFA model. Br J Sports Med [Internet]. 2005;39(6):340-6.

18. Sharma J, Greeves JP, Byers M, Bennett AN, Spears IR. Musculoskeletal injuries in British Army recruits: A prospective study of diagnosis-specific incidence and rehabilitation times Epidemiology of musculoskeletal disorders. BMC Musculoskelet Disord [Internet]. 2015;16(1):1-7.

19. Jones ABH, Hauschild VD. Musculoskeletal Training Injury Prevention in the U.S. Army: Evolution of the Science and the Public Health Approach. J Sci Med Sport [Internet]. 2018;21(11):1139-1146

20. Lerew CDR, Lerew CDR, Schmidt NB. Evaluation of Psychological Risk Factors : Prospective Prediction of Psychopathology during Basic Training. 1999;164(7):509-513.

21. Larsson H, Broman L, Harms-Ringdahl K, Larsson H, Broman L, Harms-Ringdahl K. Individual risk factors associated with premature discharge from military service. Mil Med [Internet]. 2009;174(1):9-20.

22. Dyrstad SM, Dyrstad SM, Miller BW, Halle J. Physical Fitness, Training Volume, and Self-Determined. Mil Med [Internet]. 2007;174(2):121-7.

23. Carbone CEG, Todd CS, Fiedler E. Mental Health Attrition from Air Force Basic Military Training. 1998;163(12):834-8.

24. Taanila H, Suni JH, Kannus P, Pihlajamäki H, Ruohola J-P, Viskari J, et al. Risk factors of acute and overuse musculoskeletal injuries among young conscripts: a populationbased cohort study. BMC Musculoskelet Disord [Internet]. 2015;16(1):104.

25. Nielsen RO, Bertelsen ML, Møller M, Hulme A, Windt J, Verhagen E, et al. Training load and structure-specific load: applications for sport injury causality and data analyses. $\mathrm{Br}$ J Sports Med [Internet]. 2017; bjsports-2017-097838.

26. Booth M, Orr R, Cobley S. The effect of training loads on performance measures and injury characteristics in rugby league players. A systematic review. Int J Sports Physiol Perform. 2017;32:1-44.

27. Wunderlin S, Roos L, Roth R, Faude O, Frey F, Wyss T. Trunk muscle strength tests to predict injuries, attrition, and military ability in soldiers. J Sports Med Phys Fitness. 2015;55(5):535-43. 
28. Kyrolainen H, Pihlainen K, Vaara JP, Ojanen T, Santtila M. Optimising training adaptations and performance in the military environment. J Sci Med Sport. 2018;21(11):1131-8.

29. Parkkari J, Taanila H, Suni J, Mattila VM, Ohrankämmen $\mathrm{O}$, Vuorinen $\mathrm{P}$, et al. Neuromuscular training with injury prevention counselling to decrease the risk of acute musculoskeletal injury in young men during military service: a population-based, randomised study. BMC Med [Internet]. 2011;9(1):35.

30. Reis JP, Trone DW, Macera CA, Rauh MJ. Factors associated with discharge during marine corps basic training. Mil Med. 2007;172(9):936-41.

31. Pereira MG, Galvão TF. Heterogeneidade e viés de publicação em revisões sistemáticas. Epidemiol e Serviços Saúde [Internet]. 2014;23(4):775-8.

32. Guyatt GH, Oxman AD, Kunz R, Woodcock J, Brozek J, Helfand M, et al. GRADE guidelines: 8 . Rating the quality of evidence - Indirectness. J Clin Epidemiol. 2011;64 (12):1303-10.

33. Zhang Y, Coello PA, Guyatt G, Yepes-nuñez JJ, Elie A, Hazlewood G, et al. GRADE Guidelines: 20. Assessing the certainty of evidence in the importance of outcomes or values and preferences - Inconsistency, Imprecision, and other domains. J Clin Epidemiol [Internet]. 2018;

34. Swedler DI, Knapik JJ, Williams KW, Grier TL, Jones BH. Risk factors for medical discharge from United States Army Basic Combat Training. Mil Med. 2011;176(10):1104-10.

\section{Corresponding author}

Priscila dos Santos Bunn, Avenida Brasil, 10.590, Penha, 21.012-350, Rio de Janeiro, RJ, Brazil.

E-mail: priscilabunn@yahoo.com.br.

Manuscript received on March 29, 2020

Manuscript accepted on August 18, 2020

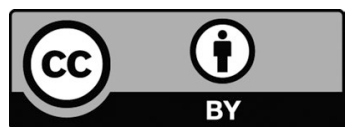

Motriz. The Journal of Physical Education. UNESP. Rio Claro, SP, Brazil - eISSN: 1980-6574 - under a license Creative Commons - Version 4.0 